\title{
Arazi Örtüsü/Arazi Kullanım Değişimlerinin Farklı Zamanlı Landsat Uydu Görüntüleri ile Belirlenmesi: Çarşamba Delta Ovası Örneği
}

\author{
İnci Demirağ Turan ${ }^{1 *}$ iD \\ Orhan Dengiz ${ }^{2}$ iD

\begin{abstract}
${ }^{1}$ Samsun Üniversitesi, İktisadi İdari ve Sosyal Bilimler Fakültesi, Coğrafya Bölümü, Samsun, Türkiye.
${ }^{2}$ Ondokuz Mayıs Üniversitesi, Ziraat Fakültesi, Toprak Bilimi ve Bitki Besleme Bölümü, Samsun, Türkiye

*Sorumlu yazar: dmrginci@ mail.com
\end{abstract}

Nursaç Serda Kaya ${ }^{2}$ iD

Geliş Tarihi: 10.01.2021

Kabul Tarihi: 03.02.2021

\section{$\ddot{\mathbf{O} z}$}

Arazi örtüsü/arazi kullanımı değişimleri araziye uygun bir şekilde yapılmadığı takdirde, ekolojide önemli tahribatlara neden olabilmektedir. Çalışmanın amacı, Samsun ilinin doğusunda yer alan ve Karadeniz Bölgesi'nin en önemli ovalarından birisini oluşturan Çarşamba Delta Ovası'nın arazi kullanımı ve arazi örtüsünün yaklaşık otuz yıllık süreçteki zamansal değişiminin uzaktan algılama tekniği kullanılarak belirlenmesidir. Çalışmada 1994, 2000, 2011, 2020 yıllarına ait Landsat uydu görüntüleri kullanılmıştır. Sınıflandırma işleminin yapılabilmesi için ENVI 5.3v programında kontrollü sınıflandırma yapılarak altı ana arazi örtüsü ve arazi kullanım sınıfları oluşturulmuş, oluşturulan sınıfların arazide kontrolleri yapılmış ve tarım, mera, orman, findık alanları, yapay yüzeyler ve su alanları olarak altı sınıf tanımlanmıştır. Arazi kullanım etkinliğinin belirlenmesi için analog veriler sayısallaştııılmış ve coğrafi bilgi sistemleri (CBS) veri tabanına aktarılmıştır. Ova üzerinde en geniş alan tarım alanlarına ait iken bunu fındık alanları ve yapay alanları izlemektedir. Özellikle yaklaşık son on yıllık süreçte yapay alanlar ve findık arazilerinde artış, mera alanlarındaki azalış olması meydana gelen arazi degradasyonuna dikkat çekmektedir. Ayrıca, bu çalışma ile geniş alanlarında arazi kullanımı ve arazi örtüsü değişiminin belirlenmiş ve kullanım eğilimlerinin izlenmesinde, uzaktan algılama ve coğrafi bilgi sitemlerinin kullanılmasıyla arazi kullanım eğilimlerinin izlenmesi önemli rol oynamaktadır.

Anahtar kelimeler: Arazi kullanımı arazi örtüsü, değişim analizi, Çarşamba Ovası

\section{Determination of Land Use/ Land Cover Changes with Multi-temporal Landsat Satellite Images: A Case Study of Çarşamba Delta Plain}

\section{Abstract}

Land cover/land use changes can cause significant damage to ecology if they are not built properly for the land. The aim of the study is to determine the temporal change in Land Use and land cover of Çarşamba Delta plain, which is located in the east of Samsun province and forms one of the most important plains of the Black Sea region, using remote sensing technique. 1994, 2000, 2011, 2020 dated Landsat image were used in this study. For performing calculations in ENVI 5.3v software supervised classification applied and six main classes were formed. For determining the unclassified classes as classified the field work applied. The result of the classification farm lands, forest, pasture, hazelnut field, water surface and artificial areas were determined as six land use-land cover classes. For determining land use efficiency analogue data were digitized and transferred to GIS database. The largest area on the plain belongs to agricultural areas, followed by hazelnut areas and artificial areas. Especially in the last decade, the increase in artificial areas and hazelnut lands, and the decrease in pasture lands focused on showing variation for the size of the areas, is important. In addition, this study showed that to determine and to monitory for large areas land cover and land use trend, remote sensing and geographic information system techniques have important role to generate accordance and fast data.

Keywords: Land use land cover, change analysis, Çarşamba Plain

\section{Giriş}

İnsanlık, ekosistemler tarafından sağlanan gıda, lif, yakıt ve diğer malzemeleri elde etmek için tabiatı sürekli dönüştürmektedir. Dünya yüzeyinin \%83'ü doğrudan veya dolaylı yoldan insan faaliyetlerinden etkilenmektedir (Sanderson ve ark., 2002). Son 40 yılda tarımsal üretim için yılda yaklaşık 4 milyon hektar doğal bitki örtüsü tahrip edilmiştir (Tilman ve ark., 2001). Bu arazi 
örtüsü/arazi kullanımı değişiklikleri, kaynakların mevcudiyeti, iklim dalgalanmaları ve çok çeşitli sosyoekonomik faktörler ile ilişkilendirilmektedir (Lambin ve ark., 2003). Orijinal arazi örtüsünün değiştirilmesi sonucu yaşanan habitat kayıpları, küresel biyoçeşitlilik krizinde önemli bir rol oynamaktadır (Sala et al., 2000; Pimm ve ark., 2000). Arazi örtü desenlerindeki değişimler ve toprak kayıpları, biyojeokimyasal döngülerin (Vitousek ve ark., 1997; Houghton ve ark., 2001) ve iklimin (Pielke ve ark., 2002; Gibbard ve ark., 2005) de değişmesine neden olmaktadır. Ekosistemlerin yapıs1 ve işleyişindeki bu sürekli değişimler, arazi örtüsü/arazi kullanımındaki küresel değişimin temel etkenlerinden biri olarak değerlendirilmektedir (Foley ve ark., 2005) ve böylece insan ihtiyaçlarını karşılamada yetersiz kalmaktadır. Bu değişim sürdürülebilir şekilde olmadığı taktirde ciddi problemlere sebep olmaktadır. Bu nedenle doğal ortama uygun bir şekilde arazilerin kullanılması ve planlanması gelecekteki arazi yönetimi için güncel arazi örtüsü/arazi kullanım bilgilerine ihtiyaç vardır (Gülersoy, 2008).

Ülkemizde arazi kullanımı sürekli bir değişim halindedir. Türkiye'de hızla artan nüfus, şehirleşme ve buna bağlı olarak sanayi faaliyetlerinin artması arazi örtüsü/arazi kullanımında oldukça fazla değişikler meydana getirmektedir. Orman ve meraların tahrip edilmesi, özellikle I. sınıf tarım alanlarının uygun kullanılmaması, kontrolsüz ve plansız bir biçimde kullanımları buna çok açık örnekler olup, arazilerde geri dönülemez tahribatlara yol açıp tahrip olmalarıyla sonuçlanmaktadır. $\mathrm{Bu}$ şekilde kaybedilen arazi varlığımız (I., II. ve III. sınıf) 573.239 hektara ulaşmış durumdadır (Cangir ve ark., 1998, Dengiz ve ark., 2006). Arazi örtüsü/arazi kullanımı değişimi ya da basit adıyla arazi değişimi, insanoğlunun yeryüzünde meydana getirdiği değişiklikler için kullanılan bir terimdir (Erle ve Pontius, 2007) ve bu durumun küresel bir hal alması, dünyanın işleyişini de önemli ölçüde etkileyebilmektedir (Lambin ve ark., 2001). Arazi örtüsünde meydana gelen değişiklikler ekosistemdeki sürdürülebilirliğe olumsuz yönde etki edebilir ve insan faaliyetleri bu sürecin hızlanmasına neden olabilecek en önemli etkenlerden biri olarak kabul edilmektedir (Agarwal ve ark., 2001). Bu nedenle arazinin uygun şekilde kullanılması için arazi kullanımındaki zamansal değişim ortaya konulup, elde edilen sonuçlarla planlamalar yapılmalı ve ona uygun şekilde yönetim anlayışı benimsenmelidir.

Bilim ve uzay teknolojilerindeki gelişmelerle hızl, güvenilir, güncel ve analiz edilebilir bilgiye ulaşmak çok daha kolaydır. Günümüzde arazi örtüsü/arazi kullanım değişimlerinin tespitinde uzaktan algilama (UA) ve coğrafi bilgi sistemlerinden (CBS) yararlanılmaktadır. UA ve CBS, arazi örtüsü/arazi kullanımı değişimlerinin gözlemlenmesinde başvurulan en etkili yöntemlerdendir. UA ve CBS'nin birlikte entegrasyonu, birçok yer bilimi çalışmalarına kaynak sağlayan arazi örtüsü/arazi kullanımlarının tespiti, zamansal ve mekânsal değişikliklerin gözlemlenmesi, planlanması ve yönetiminde de büyük kolaylıklar sağlamaktadır. Nitekim Yaseen ve Dilovan Ramadhan (2019), Irak'ın Zakho şehrinin 1987-2017 yılları arası arazi örtüsü/arazi kullanımındaki zamansal ve mekânsal değişimi, 1989 yılı Landsat Thematic Mapper (TM) ve 2017 yılı Landsat Operational Land Imager (OLI) uydu görüntüleri ile izlemiş olduğu bu çalışmada, tarım alanları, inşaat alanları, kayalık araziler, toprak arazisi ve su kütlelerinde artışlar olduğunu, diğer taraftan ormanlar ve otlak alanlarda ise azalmalar olduğunu gözlemlemiştir.

Türkiye'de de UA ve CBS tekniklerini kullanarak arazi örtüsü/arazi kullanımındaki değişimi inceleyen birçok çalışma yapılmıştır (Dengiz ve ark., 2014; Kaya ve ark., 2020; Özdemir ve ark., 2003; Bulut ve ark., 2018; Canıberk ve ark., 2014; Gülersoy 2013; Gürbüz ve ark., 2012; Topaloğlu ve ark, 2013) Dengiz ve Demirağ Turan, (2014) uzaktan algilama ve coğrafi bilgi sistemlerini kullanarak, Samsun ili Merkez İlçesinin 1984-2011 yılları arasındaki arazi örtüsü/arazi kullanımındaki zamansal değişimini belirledikleri bu çalışmada, 1984 yılı arazi kullanım türleri ile 2005 ve 2011 yıllarına ait uydu görüntülerini kullanarak belirledikleri arazi kullanım türlerini arazi kullanım kabiliyet sınıfları ile kıyaslamış ve bu kıyaslama sonucunda I., II. ve III. sınıf tarım arazilerinde nüfusun baskısıyla birlikte yerleşmeye açılmasının arttı̆̆ını; 1984 yılında 24313.76 ha olan tarım arazisinin, 2005 yılında 10120.96 hektara, 2011 y1lında ise 6960.69 hektara gerilediğini; buna karşılık 1984 yllında 1893.36 hektar olan tarım dişı arazilerin 2005 yılında 6301.662 hektara, 2011 yılında ise 7917.737 hektara yükseldiğini gözlemlemişlerdir. Benzer şekilde, Kaya ve ark., (2020) tarafından CORINE arazi örtüsü/arazi kullanım sınıflarının belirlendiği bu çalışmada, farklı konumsal çözünürlüğe sahip Landsat 8 , Sentinel 2 ve Triplesat uydu görüntülerinin CORINE arazi kullanım/arazi örtüsü sınıflamasının birinci ve ikinci düzeylerinde dağılım haritaları oluşturulmuş ve yer gerçekleri ile 
karşılaştırmaları yapılarak çalışma alanına ait kullanılan uydularda tarım alanlarının geniş yayılış gösterdiği ve ayrıca tarım ve orman alanlarının tarım dışı alanlar olarak dönüştüğü gözlemlenmiştir. Özelkan ve ark. (2018) uzaktan algılama ile kent alalarının tarım alaları üzerindeki baskısını incelemişlerdir. Kent alanlarındaki yayılmanın tarım arazileri üzerine yoğunlaştığı ve baskı yaptığı ve kentleşmedeki yayılma ile tarım alanları arasında yüksek bir negatif korelasyon olduğunu belirlemişlerdir.

Arazi örtüsü/arazi kullanımındaki sınıflandırmanın değişimi belirlemek için başka bir değerlendirme ise, Karar H. Fahad ve ark. (2020) tarafından Irak'1n Baghdad kentinin 1990-2018 yılları arasındaki arazi örtüsü/arazi kullanımının zamansal ve mekânsal değişimin gözlemlendiği bu çalışma olup, USGS'den (United States Geological Survey) temin edilen Landsat TM ve Landsat OLI8 uydu görüntüleri sınıflandırılarak kentsel alanlar, su kütleleri, tarım alanları, çıplak araziler ve sulak alanlar olmak üzere 5 ayrı arazi örtüsü sınıfı oluşturulmuş ve bu arazi örtüsü sınıflarından kentsel alanlar ve toprak arazisinin sırasıyla $\% 3$ ve $\% 20$ oranında arttığını; tarım alanlarının, sulak alanların ve su kütlelerinin ise sırasıyla \%5, \%17 ve \%1 oranında azaldığ gözlemlenmiştir. Sonam Wangyel Wang ve ark. (2020), uzaktan algılama ve coğrafi bilgi sistemlerini kullanarak, Nepal'in Kathmandu şehrinin 1990-2010 yılları arasındaki arazi örtüsü/arazi kullanımındaki zamansal ve mekânsal değişimini belirlediği ve geleceğe yönelik tahminlerde bulunduğu bu çalışmada, Kathmandu bölgesindeki ormanların \%9.28'inin, tarım alanlarının \%9.8'nin ve su kütlelerinin ise \%77'sinin kaybedildiğini gözlemlemiş bu veriler 1şığında 2030 yılı arazi örtüsü/arazi kullanımındaki değişim eğilimlerine yönelik orman, tarım ve su kütlelerinde sırasıyla \%14.43, \%16.67 ve $\% 25.83$ oranında ek bir azalma ve kentsel alanlarda ise \%18.55 oranında ek bir artış olacağı tahmininde bulunmuşlardır.

Türkiye'de bazı ovalar büyük ova koruma alanı olarak belirlenerek Bakanlar kurulunca kararla yürürlüğe konulmuştur. Çarşamba Ovası'nın da içinde bulunduğu 141 ova ilgili tarımsal potansiyeli yüksek, ancak buna karşılık erozyon, kirlilik, arazinin amacına uygun kullanılmaması gibi çeşitli nedenlerle toprak kaybı ve arazi bozulmalarının önemli bir problem olduğu ovalar büyük ova koruma alanı olarak belirlenmiştir (Anonim, 2020a). Çarşamba ovasında geçmişten günümüze nüfusun artması ile arazi üzerindeki baskı da artmaktadır. Bu anlamda büyük ova koruma alanı içindeki bir ovanın geçmişten günümüze değişimin ve bu değişimin ne yönde olduğunun ortaya konması gelecekte alınacak önlemler bakımından önemlidir.

$\mathrm{Bu}$ çalışmanın amacı, Samsun ilinin doğusunda yer alan ve Karadeniz bölgesinin en önemli ovalarından birisini oluşturan Çarşamba Delta Ovası'nın arazi kullanım ve arazi örtüsünün yaklaşık otuz y1llık (1994-2020) süreçteki zamansal değişiminin uzaktan algılama tekniği kullanılarak belirlenmesi ve mevcut arazi kullanım ve arazi örtüsü hakkında bilgi verilmesidir.

\section{Materyal ve Yöntem}

\section{Çalışma alanının genel özellikleri}

Çalışma alanını Samsun ilinin doğusunda yer alan ve büyük çoğunluğunu Yeşil ırmağın getirmiş olduğu depozitler üzerinde dağılım gösteren Çarşamba delta ovası oluşturmaktadır. Ovada Samsun'un; Tekkeköy, Çarşamba, Terme, Salıpazarı ilçelerine ait sınırlar ile Ordu ilinin Ünye ilçesinin bir miktar sınırı yer almaktadır (Şekil 1). Ayrıca çalışma sahası $41^{\circ} 03^{\prime} 24^{\prime \prime}-41^{\circ} 23^{\prime} 12^{\prime \prime}$ kuzey paralelleri ile $36^{\circ} 23^{\prime} 11^{\prime \prime}-37^{\circ} 16^{\prime} 23^{\prime \prime}$ doğu meridyenleri koordinatları arasında kalır. Alan yaklaşık olarak 106561 ha'dır.

Ova tabanındaki yerlerde eğim değerleri ortalama \%0.1 dir. Bu değer denize doğru yaklaştıkça \%0.0-0.02 ye kadar düşer. Yeşilırmak bol alüvyon taşıdı̆̆ 1 dönemde sığ şelf sahasında biriktirme yapmış ve günümüze dek birkaç kez yatak değiştirmiş̧ir (Arınç, 2011). Bu nedenle kıyının hemen gerisi yarı bataklık görünümündedir. Bataklıklardaki su birikintileri yağışlı havalarda birer küçük göl karakteri gösterecek kadar büyüktür.

Yamaç arazilerde eğim \%2-40 arasında değişmektedir. Deltanın güney kesimini Canik Dağları'nın kuzey yamaçları ile sınırlandırılmakta ve yaklaşık $50 \mathrm{~m}$ izohipsi oluşturmaktadır. Çalışma alanı içindeki 10 yıldan daha fazla verisi olan meteoroloji istasyonlarından yararlanılmıştır. Çarşamba Meydan (havaalanı) meteoroloji istasyonu verilerine göre uzun yıllık (2000-2020) ortalama sicaklık $14.3^{\circ} \mathrm{C}^{\prime}$ dir. Uzun yıllık toplam yağış miktarı ise $843 \mathrm{~mm}$ 'dir (MGM, 2020). Verimli alüviyal topraklara sahip Çarşamba Delta Ovası'nda yoğun olarak tarım yapılmaktadır. Tarımsal faaliyet 
arttıkça yerleşmeler açılmıştır. Sulak alanlarda kavak yetiştirilir. Ovada findık, tütün, mısır, çeltik, sebze, ayçiçeği, soya ve meyve üretilir.

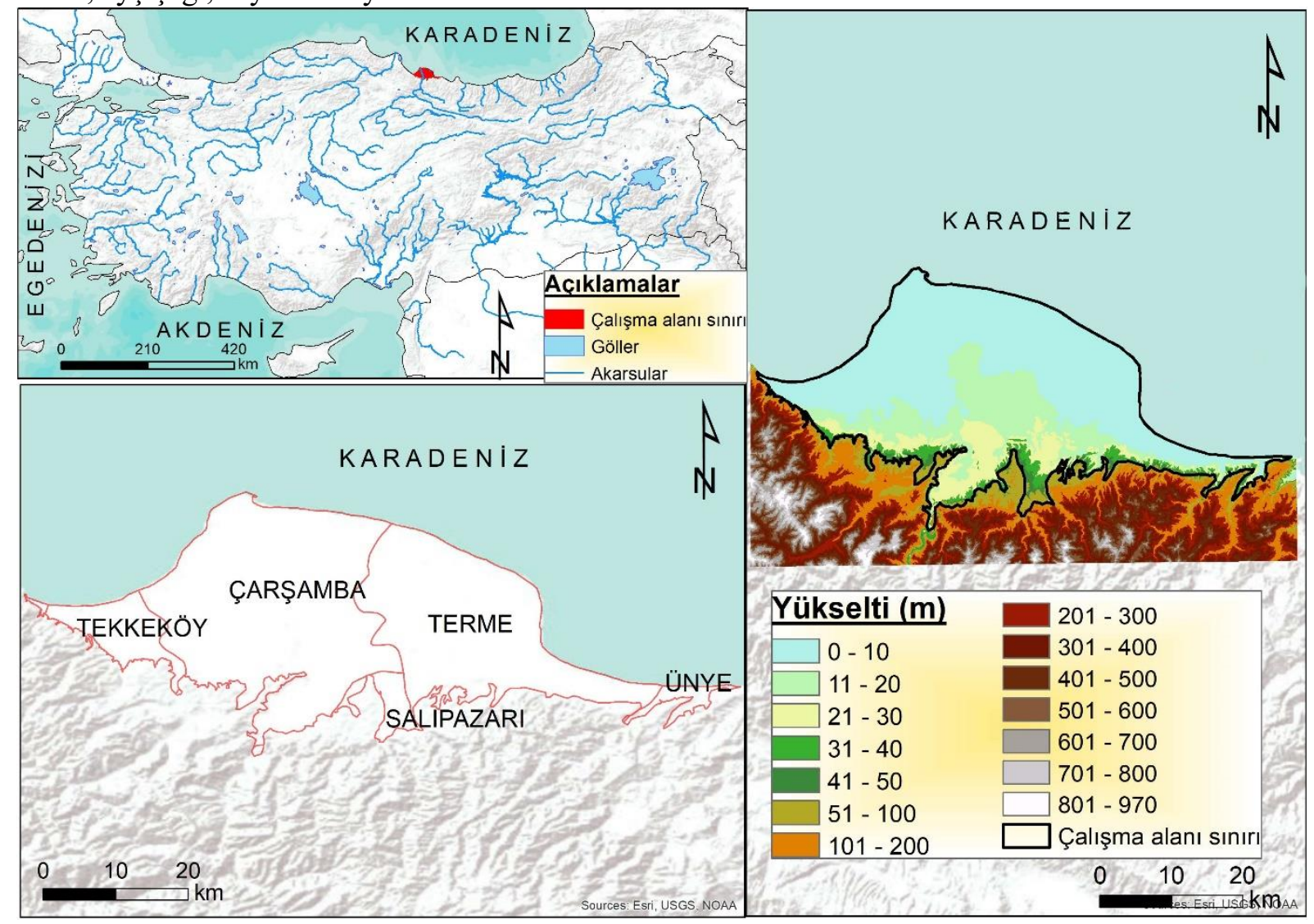

Şekil 1. Çalışma alanının lokasyon haritası.

Ova üzerinde dağılım gösteren ilçelerin 1965-2019 yılları arasında TÜíK verilerine göre nüfus özellikle Çarşamba, Terme, Tekkeköy ve Salıpazarı ilçelerinde 1965 yılında toplam 208083 kişinin yaşadığını, bu rakamın 2016 yılı itibariyle 278179'a ve 2019 yılında 282961'e ulaştığını söyleyebiliriz (Anonim, 2020b). Çalışma alanında nüfus 2000 yılına kadar sürekli artmakta, 2000 yılından sonra ise bir miktar azalmaya olduğu ancak son yıllarda tekrar arttığını söylemek mümkündür (Çizelge 1). Nüfusun bu artışı da ova üzerindeki baskıyı gün geçtikçe arttırmaktadır.

Çizelge 1. Çalışma alanındaki ilçelere ait nüfus dağılımları (Anonim, 2020b).
İlçeler

\begin{tabular}{llllllll} 
İlçeler & \multicolumn{7}{c}{ Yıllar } \\
\cline { 2 - 7 } & 1965 & 1975 & 1985 & 2000 & 2007 & 2016 & 2019 \\
Tekkeköy & - & - & - & 50.476 & 49.046 & 50.149 & 52.935 \\
Çarşamba & 129.425 & 153.266 & 175.829 & 131.194 & 136.343 & 137.739 & 138.544 \\
Terme & 79.405 & 96.411 & 103.344 & 82.608 & 74.833 & 71.577 & 71.492 \\
Salıpazarı & - & - & - & 25.113 & 20.986 & 18.714 & 19.990 \\
Toplam Nüfus & 208.083 & 249.677 & 279.173 & 289.391 & 281.208 & 278.179 & 282.961 \\
\hline
\end{tabular}

\section{Yöntem}

\section{Arazi kullanım arazi örtüsü zamansal değişim}

Çalışma alanına ait 20.05.1994, 20.05.2000 ve 20.06.2011 tarihlerine ait 30m x 30m konumsal çözünürlüğe sahip Landsat (TM) uydu görüntüleri ile 11.05.2020 tarihine ait Landsat 8 OLI-TIRS uydu görüntüleri kullanılmıştır. Sınıflandırma işleminden önce her bir uydu görüntüsü için radyometrik, atmosferik ve geometrik düzeltme işlemleri ayrı ayrı yapılmış, kontrast arttırma ve keskinleştirme gibi görüntü zenginleştirme işlemleri uygulanmıştır. 11.05.2020 tarihli Landsat 8 OLI- 
TIRS uydu görüntüsünün çözünürlüğü Pan-Sharpening işlemi ile 30 m'den 15 m çözünürlüğe yükseltilmiştir. ENVI 5.3 programında her bir uydu görüntüsü için ayrı ayrı eğitim veri setleri hazırlanmış ve görüntüler eğitimli olarak sınıflandırılmıştır. Arazi çalışmalarında her bir sınıfa ait 40 adet olmak üzere toplam 240 adet referans nokta seçilmiş ve el GPS'i ile koordinatları kaydedilmiştir. Günümüzde en çok kabul gören sınıflandırma yöntemi En Yüksek Olasılık (Maximum Likelihood) yöntemidir (Ekercin, 2007). Bu nedenle bu çalışmada görüntüler eğitimli olarak sınıflandırılırken En Yüksek Olasılık (Maximum Likelihood) yöntemi kullanılmıştır. Maksimum benzerlik metodu uygulanarak sınıflandırılan görüntüden altı farklı (fındık alanları, mera alanları, yapay yüzeyler, orman alanları, tarım alanları ve su alanları) sınıf oluşturulmuştur. Eğitimli sınıflandırma ve doğruluk analizi işlemlerinde ENVI 5.3v, haritalama işlemlerinde ise ArcGIS 10.5v programlarından faydalanılmıştır.

\section{Arazi örtüsü-arazi kullanımının zamansal değişimi}

Yapılan birçok çalışma, sınıflandırma sonrası değişimin belirlenmesi analizinin, aynı alana ait arazi örtü yoğunluğunda ve arazi kullanımının farklı zamanlarda meydana gelen değişikliklerin gözlemlenmesinde kullanılan en uygun yöntem olduğunu göstermiştir (Wickware ve Howarth 1981; Forkuo ve Frimpong, 2012; Woo ve Do, 2015). Sinıflandırma sonrası gerçekleştirilen değişimin belirlenmesi analiziyle, çalışma alanında meydana gelen arazi kullanımı/arazi örtüsü değişiklikleri tespit edilebilmekte ve dönüşüme uğrayan çalışma alanının yeni arazi kullanım türü belirlenebilmektedir. $\mathrm{Bu}$ çalışmada, eğitimli olarak sınıflandırılmış 20.05.1994, 20.05.2000, 11.06.2011 ve 11.05.2020 tarihlerine ait dört farklı Landsat uydu görüntüsü üzerinde sınıflandırma sonrası değişimin belirlenmesi algoritması kullanılarak, arazi kullanımı/arazi örtüsünde meydana gelen değişiklikler belirlenmiştir.

\section{Doğruluk analizi}

Uzaktan algılama veri ve tekniklerindeki hızlı gelişme kullanımlarının gittikçe yaygınlaşması, konumsal analizleri daha hızlı ve daha güçlü hale getirmiştir. Fakat artan konumsal heterojenlik, hata olasilıkların artmasina da neden olabilmektedir. Bu nedenle, uzaktan algilama verilerinden elde edilen haritaların doğruluğunun değerlendirilmesi, sınıflandırmayı gerçek arazi örtüsünü doğru bir şekilde yansıttığına inanılan referans verilerle karşılaştırma işlemi kritik ve önemli bir adımdır (Dağıstanlı ve ark., 2018).

Araştırma sahasına ait sınıflandırılmış her bir uydu görüntüsünün doğruluk analizleri en yaygın olarak kullanılan hata matrisi yöntemi (Fan ve ark., 2007) ile belirlenmiştir. Doğruluk analizi, araziden alınan referans noktaları ile kontrollü sınıflandırma yapılan haritayı istatistiksel olarak karşılaştıran yöntemdir. Sınıflandırma sonrası karşılaşılan hatalar, piksellerin yanlış sınıflara atanmasından dolayı meydana gelmektedir. Ayrıca, sınıflandırma sonrası doğruluk analizlerinde hata matrisi ile birçok hata ölçüsü oluşturulabilir. Kullanıcı doğruluğu, üretici doğruluğu ve genel doğruluktur en çok kullanılan hata ölçülerindendir (Yan, 2006). Kullanıcı doğruluğunun hesaplanmasında her bir sınıfa doğru olarak atanmış piksel sayısı, o kategoride sınıflandırılan toplam piksel sayısına bölünerek belirlenmiştir (Yan ve ark., 2006) (Eşitlik 1).

$$
\text { Kullanıcı Doğruluk }=\frac{n i i i}{n i k}
$$

Burada; $n_{\mathrm{ii}}$ : sınıflandırılmış piksel ve $n_{\mathrm{ik}}$ : sınıflandırılan toplam piksel anlamına gelmektedir,

Üretici doğruluğu ise her bir sınıf için doğru olarak sınıflandırılmış piksel sayısının, o sınıf için seçilen gerçek örtü tipi örnekleme sayısı toplamına (sütun toplamı) bölünmesiyle hesaplanmıştır (Eşitlik 2).

$$
\text { Üretici Doğruluk }=\frac{n i \bar{i}}{n k i}
$$

Burada; $n_{\ddot{u ̈}}$ : Doğru olarak sınıflandırılmış piksel ve $n_{k i}$ : o sınıf için seçilen gerçek örtü tipi örnekleme sayısı toplamı anlamına gelmektedir,

Bu iki değerden birinin 100'e yakın olurken diğerinin çok düşük olması ya da iki değerin de çok küçük olması seçilen oluşturulan eğitim setlerinin ya da kullanılan algoritmanın yeniden değerlendirilmesini gerektirebilir (Boyac1, 2012).

Genel doğruluk, her bir sınıf için doğru olarak sınıflandırılmış piksel sayısının, toplam referans piksel sayısına bölünmesi ile hesaplanmıştır (Eşitlik 3). 


$$
\text { Doğruluk Yüzdesi }=\frac{\sum_{k=1}^{q} n_{k k}}{n} \times 100
$$

$n_{k k:}$ :sınıflandırılmış piksel sayısı

$n$ : toplam referans piksel sayıs 1

Elde edilen sonuçlarda toplam doğruluk oranının \% 80 ve üzerinde olması sınıflandırılmanın doğru ve güvenilir olduğunu göstermektedir (Koç ve Yener, 2001; Özdemir ve Özkan, 2003).

Sınıflandırma sonrası doğruluk analizlerinde kullanılan bir başka hata ölçütü ise kappa (k) değeridir. Kappa (k) doğruluk değerinin hesaplanmasında aşağıdaki formülden yararlanılmaktadır (Eşitlik 4);

$$
K_{\text {hat }}=\frac{N \sum_{i-1}^{R} X_{i i}-\sum_{i=1}^{r}\left(X_{i+} * X_{+i}\right)}{N^{2}-\sum_{i=1}^{r}\left(X_{i+} * X_{+i}\right)}
$$

Bu eşitlikte kullanılan semboller aşağıdaki gibidir:

Bu eşitlikte kullanılan semboller:

$\mathrm{r}$ : hata matrisindeki toplam satır sayıs1,

$\mathrm{X}_{i i}$ : i. satır ve sütundaki piksel sayıs1,

$\mathrm{X}_{i}$ : i. satırdaki toplam piksel sayısı,

$\mathrm{N}$ : matrisin tamamındaki piksel sayısı

Kappa değeri 0 ile 1 arasında bir değer alır. Bu değerin 1'e yakın olması sınıflandırmanın doğru ve güvenilir olduğunu gösterir (Lillesand ve ark., 2008). Gözlemciler arası uyumu belirten k değeri aralıkları ise şöyledir: $\mathrm{k}: \leq 0.20$ ise önemsiz uyum, k: 0.21-0.40 ise minimal uyum, k: 0.41-0.60 ise orta derecede uyum, k: 0.61-0.80 ise önemli derecede uyum, k: 0.81-1.00 ise gözlemciler arasındaki uyumun tam olduğunu göstermektedir (Çelik, 2006).

Doğruluk analizlerinde dikkat edilmesi gereken hususlardan biri test alanlarının olabildiğince büyük ve homojen dağılıyor olmasıdır. İşlenmemiş veriden alınmış test pikselleri uzaktan algılanmış görüntü ile aynı tarihte alınmamış ise, değişiklikler olması nedeniyle sonuçlar tutarlı olmamaktadır. Ayrıca test alanları ve sınıflandırılmakta olan görüntü pikselleri arasındaki ölçek farkından dolayı sorunlar çıkabilir. Test pikselleri gerçeğine uygun şekilde olmalıdır. Bu nedenle hata matrisinden alınan doğruluklar bazı hatalı yorumlara sebep olabilir. Eğitimli sınıflandırma sonrasında gerçekleştirilen değişimin belirlenmesi analizi ise, aynı yerin farklı zamanlarına ait görüntüler arasındaki farklılıkların ölçülmesi, tanımlanması ve açıklanmasında başvurulan bir yöntemdir.

\section{Bulgular ve Tartışma}

\section{Arazi kullanımı ve arazi örtüsündeki zamansal değișim}

Bu çalışmada, 26 yıllık (1994-2020) süreç boyunca insan faaliyetlerinin Çarşamba Delta Ovası'nın arazi kullanım ve arazi örtüsünde üzerinde yapmış oldukları değişimin etkisi belirlenmeye çalışılmıştır. Alanda yaygın olarak bulunan altı farklı sınıf olan arazi kullanım ve arazi örtü çeşidi üzerinde durulmuş olup, 1994'den 2020 yılına kadar en geniş alanı özellikle ekilebilir tarım arazilerinin oluşturduğu görülmüştür (Çizelge 2). Ayrıca çalışma alanının yıllara ait arazi kullanımı arazi örtüsü dağılım haritaları Şekil 2'de verilmiştir. Ekilebilir tarım alanları toplam alanın 1994 'de \% 61.6, 2000 y1lında \%64.4 ve 2011 y1lında ise \%64.6'nı kısmın kaplamakta iken, 2020 y1lında bu oran \%45'e gerilemiştir. Çalışma sahasının eğimi ve yükseltisinin artış gösterdiği güney kesimleri az da olsa yer yer ormanların olduğu alanlar, 1994 yılında 2996 ha (\%2.8) iken 2020 y1lında bu miktarın \%1.6'ya indiği belirlenmiştir. Ovada mera arazisi toplam alan içerisinde en az dağılıma sahip olan alan olup, 1994 y1lında \%0.7 düzeylerinden bir miktar daha azalarak 2020 y1lında $\% 0.2$ dolayına kadar inmiştir. Ovada ikinci en geniş alanı kaplayan arazi kullanım arazi örtüsünü ise dikili tarım arazisi olarak da nitelendirilebilen fındık arazileri oluşturmaktadır. 2000 yılına kadar çoğunlukla ovanın sağ sahilinde yaygın olarak dağılım gösterirken, özellikle 2011 yılından sonra sol sahilin de yaygın olarak findık alanlarıyla kaplandığı belirlenmiştir. Fındık alanları ova üzerinde 1994 yılından 2011 yılına 
kadar toplam alanın yaklaşık dörtte biri (\%25 civarında) kadar iken, bu oranın 2020 yılında \%41'lere ulaştığ 1 görülmektedir. Bu artışın gerek ova üzerindeki nüfus artışının etkisi sonucunda oluşabileceği 2002 y1lına ait resmi gazetede yayınlanan "fındık üretiminin planlanması ve dikim alanlarının belirlenmesi ile findık yerine alternatif ürün yetiştirmeyi tercih eden üreticilerin desteklenmesine dair esas ve usuller hakkında yönetmelik, no: 24637" kapsamında en az \%6 eğim, III ve IV. Sınıf arazilerde ve maksimum $750 \mathrm{~m}$ yükseklikte yer alan araziler şeklindeki kriterlerin (Sarıoğlu ve ark, 2013), 2009 yılında kaldırılması ile findık alanlarının ova üzerindeki yayılımının daha da arttığı düşünülmektedir.

Su alanlarında yaklaşık 30 yıllık süreç içerisindeki değişim çok az düzeylerde olup 1994'de toplam alanın \%4.4'ünü kaplarken bu oran 2020 yılında $\% 4.0$ dolaylarındadır. Ova üzerinde dağılım gösteren yerleşim yerleri, yollar, havaalanı, sanayi alanı gibi yerler yapay yüzeyler olarak ifade edilmiş olup bu yüzeyler 1994 yılında \%5.7 dolayında iken 2000 yılında \%4.3'e gerilemiş, 2011 yılında ise dağılım bir miktar artış göstermiş ve \% 4.9'a ulaşmıştır. Fakat 2020 yılında ise bu oran \%8.1'e yükselerek 8857 ha alana ulaşmıştır. Ova üzerinde 1965'li y1llardan 2000'li yıllara kadar nüfusta bir artış eğilimi görülürken (Çizelge 2), 2000 ile 2016 yılları arasında azalma eğiliminde olduğu fakat 2016'dan sonra 2019'a doğru tekrar bir artış olduğu görülmektedir. Bu durum özellikle yapay yüzeylerdeki 2011 yılından sonraki artış, alan üzerinde özellikle ekilebilir tarım, mera ve orman alanlarında azalmaya buna karşın findık tarımına yönelme ile fındık arazilerinde artışa neden olmuştur.

Çizelge 2. Çarşamba Ovası'nda 1994, 2000, 2011 ve 2020 yıllarına ait arazi kullanım arazi örtüsünün alansal ve oransal dağılımlarının değişimleri.

\begin{tabular}{|c|c|c|c|c|c|c|c|c|c|c|}
\hline \multirow{3}{*}{$\begin{array}{l}\mathrm{AK} / \mathrm{AÖ} \\
\text { Findık alanları }\end{array}$} & \multicolumn{4}{|c|}{1994} & \multicolumn{2}{|r|}{2000} & \multicolumn{2}{|r|}{2011} & \multicolumn{2}{|c|}{2020} \\
\hline & \multirow{2}{*}{ ha } & \multicolumn{2}{|r|}{$\%$} & ha & 9 & ha & $\%$ & ha & \multicolumn{2}{|c|}{$\%$} \\
\hline & & 26354 & & 24.7 & 26397 & 24.8 & 25669 & 24.1 & 43740 & 41.0 \\
\hline Mera alanları & & 741 & & 0.7 & 254 & 0.2 & 526 & 0.5 & 120 & 0.2 \\
\hline Yapay alanlar & & 6081 & & 5.7 & 4581 & 4.3 & 5215 & 4.9 & 8857 & 8.1 \\
\hline Orman alanları & & 2996 & & 2.8 & 2213 & 2.1 & 2318 & 2.2 & 1665 & 1.6 \\
\hline Tarım alanları & & 65666 & & 61.6 & 68624 & 64.4 & 68839 & 64.6 & 47971 & 45.0 \\
\hline Su yüzeyleri & & 4723 & & 4.4 & 4492 & 4.2 & 3994 & 3.7 & 4308 & 4.0 \\
\hline 1oplam & & 106561 & & 100.0 & 106561 & 100.0 & 106561 & 100.0 & 106561 & 100.0 \\
\hline
\end{tabular}
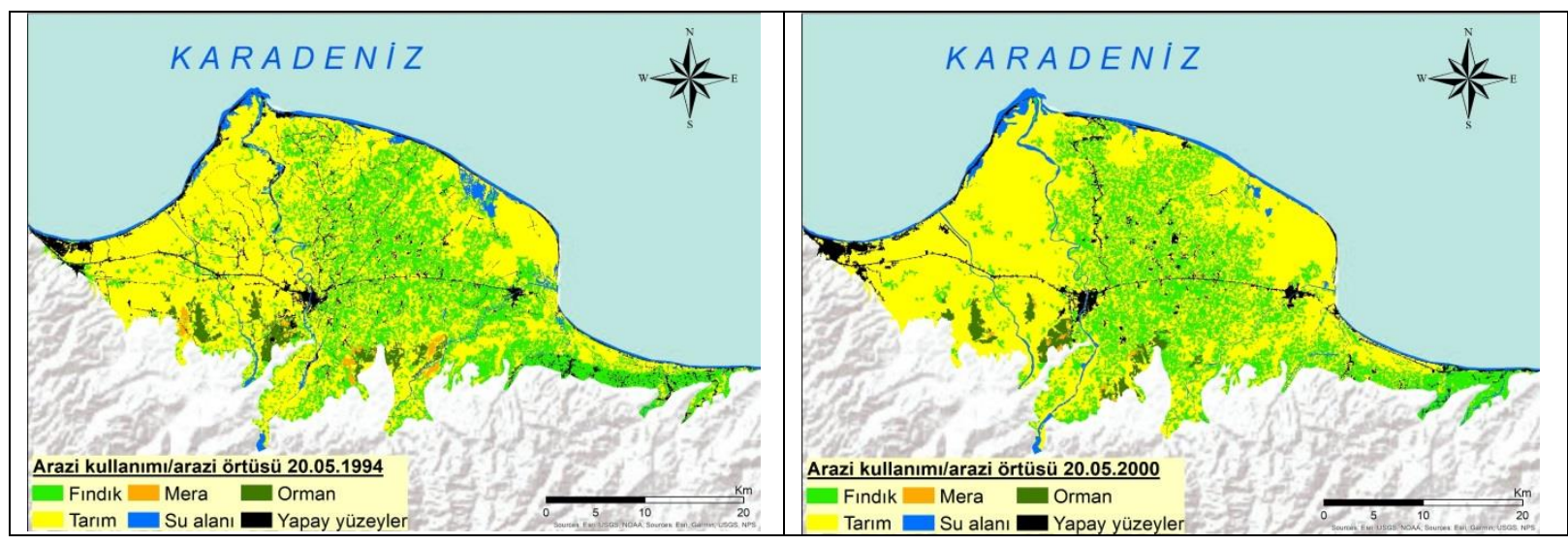

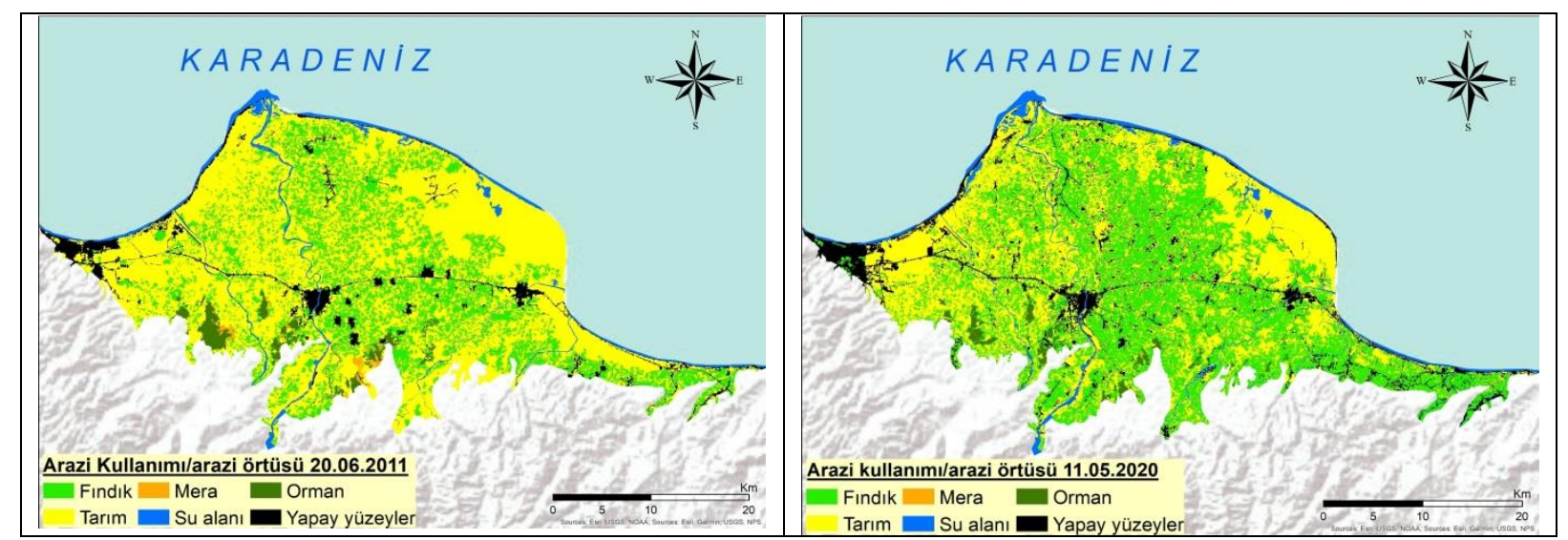

Şekil 2. Çarşamba Ovası'na ait farklı yıllardaki arazi kullanım ve arazi örtüsü dağılım haritaları

Rawat ve ark. (2014) UA ve CBS tekniklerini kullanarak arazi kullanımı/arazi örtüsündeki değişimi belirledikleri çalışmada, 1990 ve 2010 yıllarına ait iki farklı Landsat uydu görüntüsünü kullanarak 20 yıllık zaman periyodundaki değişim miktarını belirlemişler ve uydu görüntülerini ERDAS 9.3v yazılımında maximum likelihood tekniğini kullanarak eğitimli olarak sınıflandırıp; çalışma alanına ait görüntüleri vejetasyon alanları, tarım arazileri, kıraç araziler, yerleşim alanları ve su kaynakları olmak üzere 5 farklı kategoriye ayırmışlardır. 20 yıllık zaman periyodunda vejetasyon ve yerleşim alanlarının sırasıyla \%3.51 $\left(9.39 \mathrm{~km}^{2}\right)$ ve $\% 3.55\left(9.48 \mathrm{~km}^{2}\right)$ arttığını; tarım arazileri, kıraç araziler ve su kaynakları sirasiyla \%1.52 $\left(4.06 \mathrm{~km}^{2}\right)$, \%5.46 $\left(14.59 \mathrm{~km}^{2}\right)$ ve \%0.08 $\left(0.22 \mathrm{~km}^{2}\right)$ azaldığını gözlemlemişlerdir.

Abd El-Kawy ve ark. (2011) uzaktan algilama verilerini kullanarak, Batı Nil deltasının arazi kullanımı/arazi örtüsündeki değişimi belirlemek üzere 1984, 1999, 2005 ve 2009 yıllarına ait Landsat uydu görüntülerini eğitimli olarak sınıflandırmış ve sınıflandırma sonucunda kıraç arazilerin 19841999, 1999-2005 ve 2005-2009 tarihli zaman periyotlarında sırasıyla yaklaşık \%28, \%14 ve \%9'unun tarım arazilerine dönüştüğünü; bu arazi kullanımı/arazi örtüsündeki değişimlere ek olarak da insan aktiviteleri sonucunda arazide bozulmalar meydana geldiği gözlemlemiş ve daha iyi bir arazi kullanımı/arazi örtüsü yönetimi için politika önerilerinde bulunmuşlardır. Çalışma alanı için kullanılan dört farklı yıla ait görüntülerden elde edilen alansal dağılımların altı farklı eşleştirmedeki nisbi değişimleri Çizelge 3 ve Şekil 3'de verilmiştir. 1994 yılı ile 2000 yılı arasındaki 6 yıllık bir süreçte en fazla nisbi değişim mera alanlarındaki azalma olarak görülürken, \% 4.51 ile tarım alanlarında ve yine fındık alanlarında da çok az bir artış görülmektedir. 17 yıllık bir süreçte (1994-2011) ise findık alanlarında nisbi olarak \%2.6'lık bir azalma varken bu oran yapay alanlarda \%100'e ulaşmaktadır. Tarım alanlarında ise nisbi olarak bir miktar artış devam etmektedir. Fındık alanlarının ova içerisinde nisbi oranda en çarpıcı artışının ise 2000 ile 2020 yılları arasında olduğu görülmektedir ki bu durum ekilebilir tarım alanlarında, orman alanlarında ve mera alanlarında azalış olarak görülmektedir. Son olarak 26 yıllık süreç içerisinde (1994-2020) Çarşamba Ovası'nda meydana gelen arazi örtüsü arazi kullanım türlerindeki değişim itibariyle, en fazla alansal artış findık alanları ve sonrasında yapay yüzeyler üzerinde olmuştur. En fazla nisbi azalış dağılımının ise \%97.3 ile mera alanlarında olduğu ve mera alanlarını sırasıyla orman ve tarım alanlarının izlediği gözlemlenmiştir.

Çizelge 3. Arazi kullanım türlerinin yıllara göre oransal değişimi

\begin{tabular}{lcccccc} 
& \multicolumn{5}{c}{ Nisbi değişim (\%) } \\
\cline { 2 - 6 } \multicolumn{1}{c}{ Kullanım Türleri } & $1994-2000$ & $1994-2011$ & $2000-2011$ & $2000-2020$ & $2011-2020$ & $1994-2020$ \\
Fındık alanları & 0.16 & -2.60 & -2.76 & 65.70 & 70.40 & 65.97 \\
Tarım alanları & 4.51 & 4.83 & 0.31 & -30.10 & -30.31 & -26.95 \\
Orman alanları & -26.14 & -22.64 & 4.74 & -24.74 & -28.15 & -44.42 \\
Su yüzeyleri & -4.90 & -15.44 & -11.09 & -4.11 & 7.85 & -8.80 \\
Mera alanları & -65.74 & -29.05 & 107.09 & -92.20 & -96.24 & -97.33 \\
Yapay alanlar & -24.66 & -100.00 & 13.84 & 93.35 & 69.84 & 45.66 \\
\hline
\end{tabular}




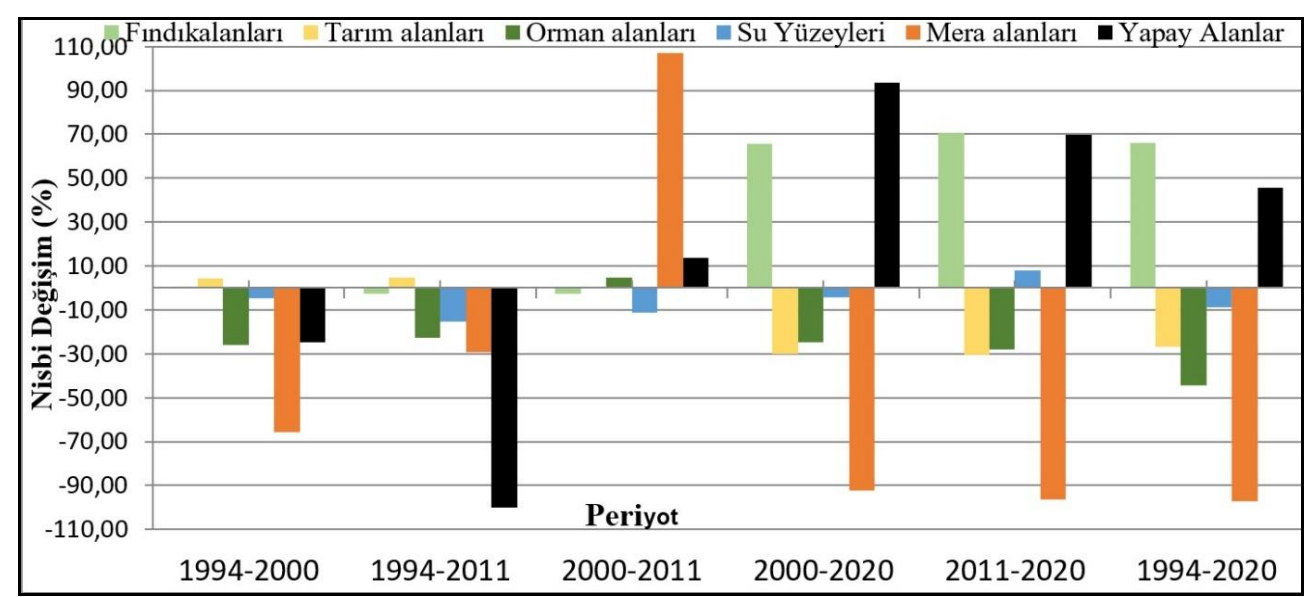

Şekil 3. Arazi kullanım türlerinin 6 farklı periyottaki nisbi değişimleri

\section{Doğruluk analizi sonuçları}

Çalışma alanına ait 20.05.1994, 20.05.2000 ve 20.06.2011 tarihli Landsat (TM) uydu görüntüleri ile 11.05.2020 tarihli Landsat-8 OLI uydu görüntüsü kullanılarak arazi kullanımının belirlenmesine yönelik yapılan doğruluk analizleri, araziden alınmış 240 adet yer kontrol noktaları belirlenmiştir. Her bir uydu görüntüsünün sınıflama sonrası elde edilen doğruluk analiz sonuçları Çizelge 4' de verilmiştir. Elde edilen sonuçlara göre 20.05.1994 tarihli uydu görüntüsünde \% 85.46 doğruluğa ulaşılmış ve çıkarımlar da bulunulmuştur. Bu değere göre sınıflandırmanın doğru ve güvenilir şeklinde yorumlanmaktadır (Koç ve Yener, 2001; Özdemir ve Özkan, 2003). Ayrıca 0.82 kappa değeri, gözlemciler arasındaki uyumun tam olduğunu göstermektedir.

Çizelge 4. Her bir uydu görüntüsünün sınıflandırma sonrası elde edilen doğruluk analiz sonuçları

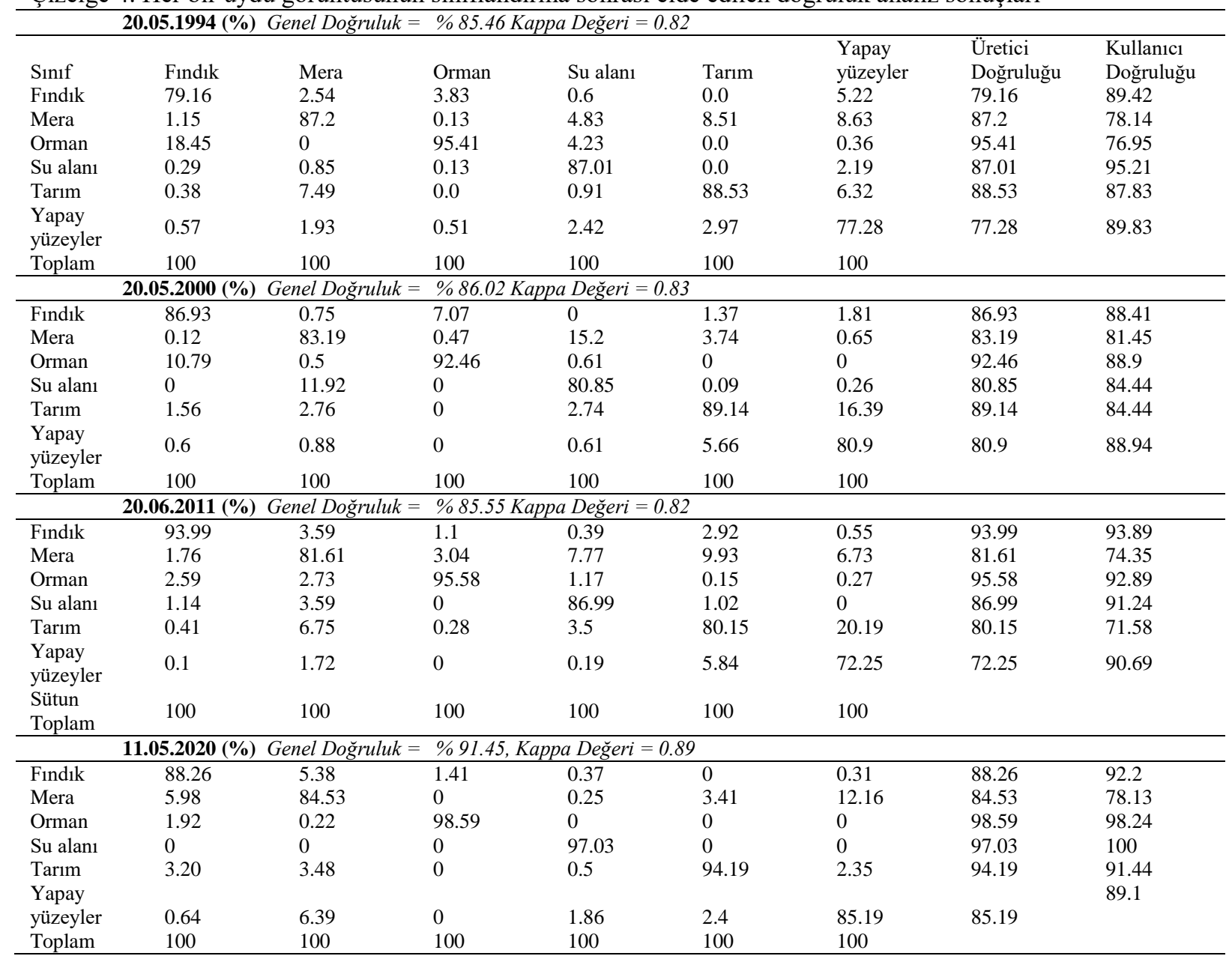


Elde edilen sonuçlardan en yüksek kullanıcı doğruluğu \% 95.21 su alanlarında çıkmıştır. Su alanlarından sonra yapay yüzeyler (\%89.83), findık (\%89.42), tarım (\%87.53), mera (\%78.14) ve orman alanları (\%76.95) gelmektedir. 20.05.2000 tarihli uydu görüntüsünde sınıflandırma sonuçları için \% 86.02 doğruluğa ulaşı1mış ve 0.83 kappa değeri ile gözlemciler arasındaki uyumun tam olduğu belirlenmiştir. Bu dönemki sonuçlarda da kullanıcı doğruluğu \% 88.94 ile yapay yüzeylerde en yüksek değer elde edilmiştir.

Yapay yüzeyleri sırasıyla; orman (\%88.9), su alanı (\%84.44), tarım (\%84.44), findık (\%88.41) ve mera alanları (\%81.45) izlemiştir. Genel sınıflama doğruluğu \% 85.55 ve kappa duyarlılığı 0.82 olan 20.06.2011 tarihli uydu görüntüsünde en yüksek kullanıcı doğruluğu \% 93.89 ile findık alanlarından elde edilmiştir. Fındık alanlarını sırasıyla; orman (\%92.89), su alanı (\%91.24), yapay yüzeyler (\%90.69), mera $(\% 74.35)$ ve tarım alanları (\%71.58) izlemiştir. 11.05.2020 tarihli uydu görüntüsünde kontrollü sınıflandırmada \% 91.45 doğruluk belirlenmiş ve kappa 0.89 ile gözlemcilerin uyumlu olduğu görülmüştür. Görüntüdeki \% 100 ile su alanlarından en iyi kullanıcı doğruluğuna ulaşılmıştır. Su alanlarını sırasıyla; orman (\%98.24), findık (\%92.2), tarım (\%91.44), yapay yüzeyler (\%89.1) ve mera alanlarının (\%78.13) izlediği gözlemlenmiştir.

\section{Sonuc}

Gerçekleştirilen bu çalışma ile Orta Karadeniz Bölgesi’nin en önemli ovalarından biri olan Çarşamba Delta Ovası'nın yaklaşık 10'ar yıllık ara ile dört farklı tarihe ait Landsat uydu görüntüsü kullanılarak yaklaşık son otuz yıllık (1994-2020) süreç içerisindeki altı farklı arazi kullanım ve arazi örtüsünde meydana gelen değişimler incelenmiştir. Uydu görüntülerine ait sınıflandırmaların doğruluk oranlarında \%85'in üzerinde bir oran elde edilmiştir. Ovada en fazla yayılım alanına sahip alanları ekilebilir tarım arazileri oluştururken, en az dağılma sahip alanları mera alanları oluşturmaktadır. Değişimlerin karakteristikleri irdelendiğinde, 1994 ile 2011 yılları arasındaki en fazla değişim mera ve orman alanlarında olurken, özellikle son on yıllık süreçte yapay alanlar ve findık arazilerindeki artış, mera alanlarındaki azalış dikkat çekmektedir. Bu değişim üzerinde ovada yer alan ilçelerdeki nüfus artışının da etkili olduğu söylenebilir.

Çalışmanın sonuçları, Samsun Çarşamba Delta Ovası'nın yaklaşık son otuz yıllık süreçte yapay alanlar ve fındık arazilerine odaklı arazi örtüsü arazi kullanım değişiminin çok daha fazla olduğunu ortaya çıkarmıştır. Elde edilen çalışmaya ait bulgularının ve uygulanan yaklaşımın, kısa süreç içerisinde güvenilir ve doğru bir biçimde zamana bağlı değişimleri belirleyebilmede, yetkililerin ve karar vericilerin yönetimsel faaliyetlerinde en önemli altlık olarak kullanılabilecek mekânsal verisinin zamansal boyutu ile değerlendirilmiş olması önemli bir kaynak olabileceği düşünülmektedir. Çalışmanın gelecekte daha yüksek mekânsal, zamansal ve spektral çözünürlüğe sahip uydu verileri ile farklı zamanlar kullanılarak geliştirilmesi önerilebilir.

\section{Kaynaklar}

Abd El-Kawy, O.R., Rød, J.K., Ismail, H.A., Suliman, A.S. 2011. Land use and land cover change detection in the Western Nile Delta of Egypt using remote sensing data. April 2011. Applied Geography 31(2):483494.

Agarwal, C., Green, G.L., Grove, M., Evans, T., Schweik, C. 2001. A Review and Assessment of Land-Use Change Models Dynamics of Space, Time, and Human Choice. Gen. Tech. Rep. NE-297. Newton Square, PA: U.S. Department of Agriculture, Forest Service, Northeastern Research Station. 61 p.

Anonim, 2020a. Bakanlar kurulu karar1. https://www.resmigazete.gov.tr/eskiler/2017/01/20170121M1.pdf. Erişim Tarihi: 30.12 .2020 .

Anonim, 2020b. Nüfus ve demografi İstatistikleri. Türkiye İstatistik Kurumu (TÜiK), https://data.tuik.gov.tr/Kategori/GetKategori?p=nufus-ve-demografi-109\&dil=1. Erişim Tarihi: 20.12.2020.

Arınç, K. 2011. Türkiye'nin Kıyı Bölgeleri, Biyosfer Araştırmaları Merkezi, Coğrafya Araştırmaları Serisi: 102, Eser Ofset Matbaacilik, Erzurum.

Boyac1, D. 2012. CBS-uzaktan algilama entegrasyonu ve örnek uygulama: Uydu görüntülerinden detay ve otomatik Öznitelik tespiti. Doktora tezi, Selçuk Üniversitesi Fen Bilimleri Enstitüsü, Konya. 
Bulut, H., Demirör, Z., Alan, İ., Kaya, Ş., Bilgin, N., Öztaş, Z., Gürçayır, E., Darende, V., 2018. 2018 Yı11 İzmir Meteorolojik Radar Verilerinin Zamansal ve CORINE Arazi Sınıflarına Göre Değişiminin Coğrafi Bilgi Sistemleri ile Analizi. Meteoroloji Genel Müdürlüğü Yazılım Geliştirme Şube Müdürlüğü, Ankara.

Cangir, C., Kapur, S., Boyraz, D., Akça, E. 1998. Türkiye'de arazi kullanımı, tarım topraklarının sorunları ve optimum arazi kullanım politikaları. M. Şefik Yeşilsoy International Symposium on Arid Region Soil, Menemen, İzmir, Turkey.

Canıberk, M., Kiracı, A.C. 2014. Arazi kullanımının zamansal değişiminin tarihi ortofotolarla belirlenmesi: Elmalı havzası örneği. 5. Uzaktan Algılama-CBS sempozyumu, 14-17 Ekim 2014, İstanbul.

Çelik, H. 2006. İstanbul Sarıyer ilçesine ait uzaktan algılama uydu verileri ile mekansal veri analizleri. Yüksek lisans tezi, Çanakkale Onsekiz Mart Üniversitesi, Fen Bilimleri Enstitüsü, Çanakkale.

Dağıstanl, C., Demirağ Turan, İ., Dengiz, O. 2018. Evaluation of the suitability of sites for outdoor recreation using a multi-criteria assessment model. Arabian Journal of Geosciences.11:492.

Dengiz, O., Turan, İ.D. 2014. Uzaktan algılama ve coğrafi bilgi sistem teknikleri kullanılarak arazi örtüsü / arazi kullanımı zamansal değişiminin belirlenmesi: Samsun Merkez ilçesi örneği (1984-2011). Türkiye Tarımsal Araştırmalar Dergisi. 1(1): 78-90.

Dengiz, O., Usul, M., Keçeci, M. 2006. Atatürk orman çiftliği arazilerinin tarımsal kullanım durumlarının değerlendirilmesi. OMÜ Zir. Fak. Dergisi. 21(1): 55- 64.

Ekercin, S. 2007. Uzaktan algılama ve coğrafi bilgi sistemleri entegrasyonu ile Tuz Gölü ve yakın çevresinin zamana bağlı değişimi. Doktora tezi, İstanbul Teknik Üniversitesi, Fen Bilimleri Enstitüsü, İstanbul.

Erle, E., Pontius R. 2007. "Landuse and landcover change." In: Encyclopedia of Earth. Eds. Cutler J. Cleveland (Washington, D.C.: Environmental Information Coalition, National Council for Science and the Environment).

Fahad K.H., Hussein S., Dibs H. 2020. Spatial-temporal analysis of land use and land cover change detection using remote sensing and gis techniques. conference: 1op conference series: materials science and engineering. 671(1).

Fan, F., Weng, Q., Wang, Y. 2007. Land use land cover change in Guangzhou, China, from 1998 to 2003, based on Landsat TM/ETM+ imagery. Sensors. 7:1323-1342.

Foley, J.A., Defries, R.S., Asner, G.P., Barford, C.C., Bonan, G., Carpenter, S.R., Chapin III, F.S., Coe, M.T., Daily, G.C., Gibbs, H., Helkowski, J.H., Holloway, T., Howard, E.A., Kucharik, CJ., Monfreda, C., Patz, J., Prentice, I.C., Ramankutty, N., Snyder, P.K. 2005. Global Consequences of Land Use. August 2005. Science. 309(5734):570-4.

Forkuo, E. K., Frimpong, A. 2012. Analysis of forest cover change detection. International Journal of Remote Sensing Applications. 2(4): 82-92.

Gibbard, S., Caldeira, K., Bala G., Phillips, T.J., Wickett, M. 2005. Climate effects of global land cover change. Geophysical Research Letters, (32):23705.

Gülersoy, A.E. 2008. Bakırçay Havzası'nda doğal ortam koşulları ile arazi kullanımı arasındaki ilişkiler. Yayımlanmamış Doktora Tezi, D.E.Ü. Eğitim Bilimleri Enstitüsü, İzmir.

Gülersoy, A.E. 2013. Farklı uzaktan algılama teknikleri kullanılarak arazi örtüsü/kullanımında meydana gelen değişimlerin incelenmesi: Manisa Merkez İlçesi Örneği (1986-2010). Turkish Studies Academic Journal. 8: 1915-1934.

Gürbüz, M., Denizdurduran, M., Karabulut, M., Kızılelma, Y. 2012. Uzaktan algıllama ve CBS kullanarak Elbistan Ovasında arazi kullanımı/arazi örtüsünde meydana gelen değişimlerin incelenmesi. KSÜ Mühendislik Bilimleri Dergisi. 30-37.

Houghton, J.T., Ding, Y., Griggs, D.J., Noguer, M., van der Linden, P.J., Dai, X., Maskell, K., Johnson, C.A. 2001. Climate Change 2001: The Scientific Basis. Cambridge University Press, Cambridge, United Kingdom and New York, NY, USA, 881pp.

Kaya, N.S., Turan, İ.D., Dengiz, O., Saygın, F. 2020. Farklı Konumsal Çözünürlüğe Sahip Uydu Görüntüleri Kullanarak CORINE Arazi Örtüsü/Arazi Kullanım Sınıflarının Belirlenmesi. Türkiye Tarımsal Araştırmalar Dergisi - Turkish Journal of Agricultural Research. 7(2): 207-218.

Koç, A., Yener, H., 2001. Uzaktan algılama verileriyle İstanbul çevresi ormanlarının alansal ve yapısal değişikliklerinin saptanması. İstanbul Üniversitesi, Orman Fakültesi Dergisi. Seri A, 51(2): 17-36.

Lambin, E.F., Geist, H.J., Lepers, E. 2003. Dynamics of Land-Use and Land-Cover Change in Tropical Regions. Annual Review of Environment and Resources, Vol. 28: 205-241.

Lambin, E.F., Turner, B.L., Geista, H.J., Agbolac, S.B., Angelsend, A., Brucee, J.W., Coomesf, O.T., Dirzog, R., Fischer, G., Folkei, C., Georgej, P.S., Homewoodk, K., Imbernonl, J., Leemansm, R., Lin, X., Morano, E.F., Mortimorep, M., Ramakrishnanq, P.S., Richardsr, J.F., Skanes, H., Steffent, W., Stoneu, G.D., Svedinv, U., Veldkampw, T.A., Vogelx, C., Xuy, J. 2001. The causes of land-use and land-cover change: moving beyond the myths. Global Environmental Change. 11: 261-269. 
Lillesand, T., Kiefer, R., and J. Chipman, 2008. Remote Sensing and Image Interpretation, 6th ed., New York, NY: John Wiley \& Sons, 756 p.

Meteoroloji Genel Müdürlüğü (MGM). 2020. Çarşamba Meydan istasyonu meteorolojik verileri.

Özdemir, İ., Özkan, Y.U. 2003. Armutlu Orman İşletme Şefliği’ndeki orman alanlarındaki değişimin LANDSAT uydu görüntülerinin kullanılarak değerlendirilmesi. Süleyman Demirel Üniversitesi Orman Fakültesi Dergisi. 1: 55-66.

Özelkan, E., Sağlık, A., Sümer, S.K., Bedir, M., Kelkit, A. 2018. Kentleşmenin tarım alanları üzerine etkisinin uzaktan algılama ile incelenmesi - Çanakkale Örneği, ÇOMÜ Ziraat Fakültesi Dergisi. (COMU J. Agric. Fac.). 6 (1): 123-134.

Pielke, P.A., Marland, S.G., Betts, R.A., Chase, T.N., Eastman, J.L., Niles, J.O., Niyogi, D.D.S., Running, S.W. 2002. The influence of land-use change and landscape dynamics on the climate system: Relevance to climatechange policy beyond the radiative effect of greenhouse gases. Phil. Trans. R. Soc. Lond. A. 360: $1705-1719$.

Pimm, S.L., Raven, P. 2000. Biodiversity - Extinction by numbers, Nature. 403(6772): 843-5.

Rawat, J.S., Kumar, M., Biswas, V., 2014. Land use/cover dynamics using multi- temporal satellite imagery: a case study of Haldwani Town area, district Nainital, Uttarakhand, India. Inter. Journal of Geomtry and Geosciences, 4 (3): 536-543.

Sala, O.E., III Chapin, F.S., Armesto, J.J., Berlow, E.L., Bloomfield, J., Huenneke, L., Jackson, RB., Kinzig, A., Leemans, R., Lodge, D.M., Mooney, H.A., Oesterheld, M., Poff, N.L., Sykes, M.T., Walker, B., Walker, M., Wall, D.H. 2000. Biodiversity: global biodiversity scenarios for the year 2100, Science. 287(5459):1770-1774.

Sanderson, E.W., Jaiteh, M., Levy M. A., Redford, K.H., Wannebo, A.V., Woolmer, G. 2002. The human footprint and the last of the wild: the human footprint is a global map of human influence on the land surface, which suggests that human beings are stewards of nature, whether we like it or not BioScience. 52(10): 891-904.

Sarığlu, F.E., Saygın, F., Balcı, G., Dengiz, O., Demirsoy, H. 2013. Determination of potential hazelnut plantation areas based GIS model case study: Samsun city of central Black Sea region. Eurasian Journal of Soil Science. 2 (1): 12-18.

Tilman, D.A., Reich, P.B., Knops, J.M.H., Wedin, D.A., Mielke, T., Lehman, C.L. 2001. Diversity and productivity in a long-term grassland experiment. Science. 294(5543): 843-5.

Topaloğlu, R.H., Ekercin, S. 2013. Coğrafi bilgi sistemi ve uzaktan algılama entegrasyonu ile konya kapalı havzası'nda arazi örtüsü/kullanımı zamansal değişimlerinin belirlenmesi. TMMOB Coğrafi Bilgi Sitemleri Kongresi, 11-13 Kasım 2013, Ankara.

Vitousek, P.M., Mooney, H.A., Lubchenco, J., Melillo, J.M., 1997. Human domination of earth's ecosystems. Science. 277.

Wang, S.W., Gebru, B.M., Lamchin, M., Kayastha, R.B., Lee, W.K., 2020. Land use and land cover change detection and prediction in the kathmandu district of nepal using remote sensing and GIS. Sustainability. 12, 3925 .

Wickware, G. M., Howarth, P. J. 1981. Change detection in the Peace-Athabasca delta using digital Landsat data. Remote Sensing of Environment. 1, 9-25.

Woo, D. M., Do, V. D., 2015. Post-classification change detection of high resolution satellite images using AdaBoost classifier. Advanced Science and Technology Letters. 117: 34-38.

Yan, G., Mas, J.F., Maathuis, B.H., Xiangmin, Z., Van Dijk, P. M. 2006. Comparison of pixelbased and objectoriented image classification approaches-a case study in a coal fire area, Wuda, Inner Mongolia, China.

Yaseen T.M., Dilovan Ramadhan, İ. 2019. Land use land cover change in zakho district, kurdistan region, 1raq: past, current and future. conference: 2019 International Conference on Advanced Science and Engineering (ICOASE). 